\title{
Proteção do recém-nascido contra o tétano pela imunização ativa da gestante com antitoxina tetânica: estudo original de 1953
}

\author{
Protection of newborn infants against tetanus by active immunization of the pregnant women with \\ tetanus antitoxin: the 1953 original study
}

Augusto Gomes Mattos ${ }^{1}$, Carlos da Silva Lacaz², Maria Aparecida S. Zacchi , Paulo Gorga ${ }^{4}$

\section{RESUMO}

Objetivo: Determinar, em cobaias prenhes e em gestantes, a produção de antitoxina tetânica induzida pela aplicação da anatoxina tetânica e estudar a sua passagem para o recémnascido.

Métodos: Na primeira fase, em estudo experimental, cobaias prenhes foram vacinadas com duas doses de toxóide tetânico em um intervalo de 15 dias, seguida da dosagem de anticorpos na cobaia imunizada, na prole ao nascer e 15 dias após o nascimento. Outro grupo de animais previamente vacinado recebeu uma dose de reforço 30 dias antes do parto, medindo-se o nível de anticorpos na cobaia e na prole. $\mathrm{Na}$ segunda fase, em ensaio clínico, as gestantes humanas foram vacinadas com três injeções de anatoxina tetânica, com um intervalo de 30 dias, em qualquer período da gravidez, medindo-se, a seguir, a antitoxina tetânica. Nos recém-nascidos, os anticorpos foram medidos ao nascer e aos 15 dias de vida.

Resultados: O título de antitoxina no sangue da prole de cobaias vacinadas com anatoxina tetânica foi elevado ao nascimento e aos 15 dias de vida. A dose de reforço provocou elevação do título basal. Nas gestantes, a aplicação de três doses de toxóide antitetânico conferiu imunidade a 95\% dos recém-nascidos estudados. Os recém-nascidos de mães vacinadas apresentaram títulos elevados de antitoxina que persistiram por mais de 15 dias de vida.

Conclusões: A vacinação durante a gestação foi acompanhada de títulos protetores de antitoxina contra o tétano tanto nos filhotes de cobaias quanto nos recém-nascidos humanos.

Palavras-chave: recém-nascido; tétano; imunização; toxóide tetânico.

Instituição: Clínica Infantil do Ipiranga. São Paulo, SP, Brasil

'Diretor clínico da Clínica Infantil do Ipiranga (1932-1975). In memorian. São Paulo, SP, Brasil

${ }^{2}$ Diretor do Instituto Pinheiros (1953). In memorian. São Paulo, SP, Brasil

${ }^{3}$ Chefe de Clínica da Clínica Infantil do Ipiranga (1945-1970). In memorian. São Paulo, SP, Brasil

${ }^{4}$ Chefe do Serviço de Pré-Natal da Clínica Infantil do Ipiranga (1950-1970).

In memorian. São Paulo, SP, Brasil

\section{ABSTRACT}

Objective: To measure, in pregnant guinea pigs and women, the production of tetanus antitoxin, induced by vaccination with tetanus toxin, and to study the transmission of these antibodies to the offspring.

Methods: In an experimental design, pregnant guinea pigs were vaccinated with two doses of tetanus toxoid with a 15-day interval followed by determination of antibodies in the immunized guinea pig, in the offspring at birth and after 15 days of life. One group of guinea pigs received a booster dose of tetanus toxoid 30 days before delivery and the immunization status of dam and offspring was also studied. In a clinical trial, pregnant women were vaccinated in any period of gestation with three doses of tetanus toxoid with a 30-day interval; the antibody levels were measured in the mother and in the newborn infant at birth and at the $15^{\text {th }}$ day of life.

Results: The antibody levels of guinea pigs offspring immunized with tetanus toxoid during gestation were elevated at birth and at the $15^{\text {th }}$ day of life. These levels were elevated by the booster dose 30 days prior to delivery. In pregnant women, the immunization with three doses of tetanus toxoid was followed by immunity in $95 \%$ of the studied infants studied. The newborn infants of vaccinated women presented elevated levels of antibodies at birth and at $15^{\text {th }}$ day of life.

Conclusions: Vaccination during gestation was followed by protective levels of antibodies in guinea pigs and in newborn infants.

Key-words: infant, newborn; tetanus; immunization; tetanus toxoid.

\footnotetext{
Endereço para correspondência:

Jayme Murahovschi

Rua José Maria Lisboa, 915

CEP 01423-001 - São Paulo/SP

E-mail: jmura@osite.com.br
}

Recebido em: 8/7/2008

Aprovado em: 2/10/2008 


\section{Introdução}

A análise detalhada dos precários dados estatísticos disponíveis permite afirmar que o "tétano umbilical é um dos graves problemas de saúde pública que aflige nosso país". Em pesquisa realizada em 1951, Gomes de Mattos et al estudaram o comportamento de cobaias recém-nascidas em relação à contaminação experimental do umbigo com diversas espécies de germes. A pesquisa, efetuada com a exposição de coto umbilical de cobaias a culturas de Clostridium tetani, estafilococos hemolíticos, Pseudomonas aeruginosa e Escherichia coli, mostraram que somente o Clostridium tetani foi capaz de produzir o tétano neonatal.

Na série de Rapports Techniques da Organização Mundial de Saúde (OMS) de 1960, encontra-se a seguinte sugestão para pesquisa: "Dans les régions présentant une fréquence elevée de tétanos des nouveaus-nés, il faudrait étudier les possibilités de prevenir cette affection ou moyen de la vaccination des femmes enceintes".

Assim, a presente pesquisa foi realizada inspirada pela OMS e teve como objetivo verificar, em cobaias prenhes e em gestantes, a produção de antitoxina específica, induzida pela aplicação da anatoxina tetânica, e a passagem do referido anticorpo para o recém-nascido e sua titulação.

\section{Métodos}

Este estudo foi constituído de uma parte experimental, realizada em cobaias, e uma parte clínica, realizada em gestantes.

\section{Estudo experimental em cobaias}

\section{Verificação da passagem de antitoxina tetânica da mãe ao feto}

Para a realização dessa experiência, cobaias prenhes foram imunizadas com duas doses de $0,50 \mathrm{~cm}^{3}$ de toxóide tetânico, com intervalo de 15 dias. As cobaias prenhes e seus filhotes foram divididos em grupos. Após a imunização, as cobaias eram sangradas, o soro era misturado e feita a titulação da antitoxina tetânica. Simultaneamente, fazia-se a dosagem da antitoxina tetânica na mistura de soro das cobaias recémnascidas, em geral, em três a cinco delas.

\section{Verificação do número de unidades de antitoxina} tetânica no soro de cobaias de 15 dias de vida, a fim de se estudar a duração do título

Grupos de cobaias prenhes eram imunizados com duas doses de $0,50 \mathrm{~cm}^{3}$ cada de toxóide tetânico, com 15 dias de intervalo. No momento do parto, era feita a sangria dos animais e a determinação do título de antitoxina. Quinze dias depois, com a mistura de soros dos filhotes cobaia (dois a três por cobaia prenhe), era novamente titulada a antitoxina tetânica.

\section{Cobaias prenhes, anteriormente vacinadas com} toxóide tetânico recebiam $0,50 \mathrm{~cm}^{3}$ como dose de reforço, 30 dias antes do parto

Eram procedidas as titulações de antitoxina tetânica no soro da cobaia prenhe, no momento do parto, e no soro das cobaias recém-nascidas, a fim de se verificar o efeito estimulante da dose de reforço sobre a passagem de anticorpos da mãe ao feto.

\section{Estudo em gestantes}

\section{Verificação do nível de antitoxina em mulheres} grávidas vacinadas com anatoxina tetânica

Foram aplicadas três injeções intramusculares de $1 \mathrm{~cm}^{3}$ de anatoxina tetânica precipitada pelo alume, com intervalo de 30 dias entre as doses, em qualquer período da gravidez, com exceção do oitavo e nono meses. Foram realizadas quatro coletas de sangue para dosar a antitoxina tetânica, sendo uma delas feita antes da primeira injeção e, as outras, 30 dias após cada dose da vacina.

\section{Verificação da influência da dose de reforço sobre o título de antitoxina na mulher grávida}

Fazia-se uma aplicação de injeção intramuscular com $1 \mathrm{~cm}^{3}$ de anatoxina tetânica, no sétimo ou oitavo mês, em mulheres que tinham imunidade básica contra o tétano. Procedia-se a retirada de sangue antes da injeção de reforço e outra dose era aplicada 30 dias depois para titulação da antitoxina.

\section{Verificação das reações e de possíveis influências sobre a evolução da gravidez, do parto e do feto}

As mulheres vacinadas eram informadas de que deveriam relatar tudo o que sentissem após cada injeção para que fosse devidamente anotado. A evolução da gravidez era objeto de inquérito, assim como as condições do recém-nascido.

\section{Experiências em recém-nascidos}

1. Verificação do título de antitoxina no sangue do cordão umbilical em recém-nascidos de mães vacinadas e não-vacinadas com toxina tetânica

Foram procedidas titulações de antitoxina tetânica em um grupo de recém-nascidos oriundo de mães vacinadas e não-vacinadas contra o tétano. 


\section{Experiências em crianças}

\section{Verificação da evolução do título de antitoxina} tetânica em crianças cujas mães foram vacinadas e cujo título fora determinado no sangue do cordão

Em crianças de várias idades que tinham título de anticorpos para tétano já determinado no sangue do cordão, era procedida uma ou mais titulações da antitoxina em sangue de punção venosa.

\section{Verificação da evolução do título de antitoxina no sangue de crianças de mães vacinadas, independente de comparação com o título do sangue do cordão}

Coletava-se o sangue de crianças cujas mães haviam sido vacinadas e fazia-se a titulação de antitoxina.

\section{Resultados e discussão}

\section{Experiências realizadas em cobaias}

O título de antitoxina encontrado no sangue de filhotescobaia cujas mães haviam sido vacinadas com anatoxina tetânica foi tão elevado que nos levou a supor que a anatoxina atravessa a barreira placentária da cobaia e leva à formação de antitoxina no filhote-cobaia, junto aos anticorpos passivamente transferidos. A titulação de antitoxina 15 dias após o nascimento revelou um teor ainda satisfatório.

Essas experiências demonstraram com eloqüência o estímulo exercido pela dose de reforço sobre o título de antitoxina nas cobaias previamente imunizadas, cujos títulos chegaram a atingir 14 unidades por $\mathrm{cm}^{3}$ de soro. Os títulos obtidos nos filhotes-cobaia foram também os mais elevados entre as experiências realizadas.

\section{Estudo em gestantes}

O tempo necessário para a realização deste estudo foi de três anos. Durante a sua execução surgiram muitas dificuldades, que acabaram por resultar em preciosas perdas de material, apesar da dedicação e do espírito de previsão daqueles que colaboraram com a pesquisa. É conhecida a dificuldade de controle sobre o material humano em serviços de ambulatório. As três etapas em que se dividia o trabalho feito com o material humano se passavam em pontos distantes: a vacinação foi feita em um Serviço PréNatal; em seguida, as mulheres eram encaminhadas a uma determinada maternidade e o sangue coletado era remetido a um Instituto Científico onde se procedia a titulação da antitoxina tetânica. De cerca de 200 mulheres grávidas que iniciaram a vacinação, 134 fizeram as três doses de anatoxina tetânica e se submeteram às quatro retiradas de sangue. Em virtude das perdas ocorridas no transporte do material e de outras causas, só foi possível aplicar as quatro dosagens em 96 casos. Destas 134 mulheres, apenas 60 deram à luz na maternidade onde o estudo foi realizado. As demais tiveram os filhos em casa ou em outras maternidades não participantes do trabalho. Das 60 crianças nascidas na maternidade participante do trabalho, só foi possível obter o sangue do cordão umbilical de 42 delas, sendo as perdas motivadas por quebra ou esquecimento da parteira em retirar o sangue. Das 42 crianças das quais se conseguiu a titulação da antitoxina tetânica no cordão umbilical, apenas em cinco foi possível repeti-la posteriormente para verificação do tempo de duração do título. Não obstante, das 134 mulheres grávidas vacinadas, apenas cinco tiveram uma segunda gravidez no decurso do trabalho e receberam a dose de reforço da anatoxina tetânica, não sendo possível conseguir um só sangue do cordão de seus recém-nascidos. Das 32 crianças de mães devidamente vacinadas, nas quais se conseguiu, em várias idades, dosar a antitoxina tetânica no sangue obtido por punção venosa, foi possível repeti-la posteriormente apenas em cinco.

$\mathrm{O}$ comportamento individual das gestantes frente à resposta imunitária sofreu variações muito grandes, como o esperado. Entre as respostas imediatas e as mais retardadas, pode-se observar uma série de situações intermediárias que dispensam qualquer realce. Contudo, cumpre desde já assinalar que, 30 dias após a terceira dose de anatoxina, as 112 gestantes que fizeram a quarta dosagem de antitoxina tinham atingido título acima de $0,01 \mathrm{U} / \mathrm{cm}^{3}$, suficiente para sua proteção.

O exame da Figura 1 oferece visão de conjunto. Observando-se o deslocamento dos pontos na escala de dosagem, pode-se notar que a massa dos casos partiu de dosagens abaixo de $0,001 \mathrm{U} / \mathrm{cm}^{3}$ e foi se deslocando, após a quarta dosagem, para cima de $0,01 \mathrm{U} / \mathrm{cm}^{3}$.

O efeito de uma dose de reforço sobre o título de antitoxina foi testado em cinco mulheres já imunizadas e que receberam a dose de reforço. No entanto, em virtude das perdas ocorridas nas dosagens, não foi possível estabelecer uma conclusão. Nos poucos dados apreciáveis, verificou-se resposta imunitária satisfatória, assim como a passagem de antitoxina para o feto.

Das 150 gestantes vacinadas, $48(32 \%)$ apresentaram reações, provavelmente decorrentes da aplicação de toxóide precipitado pelo alume. As reações referidas pelas gestantes foram: dor local, febre, calafrios, cefaléia, mal-estar, insônia, dores diversas e vômitos. 


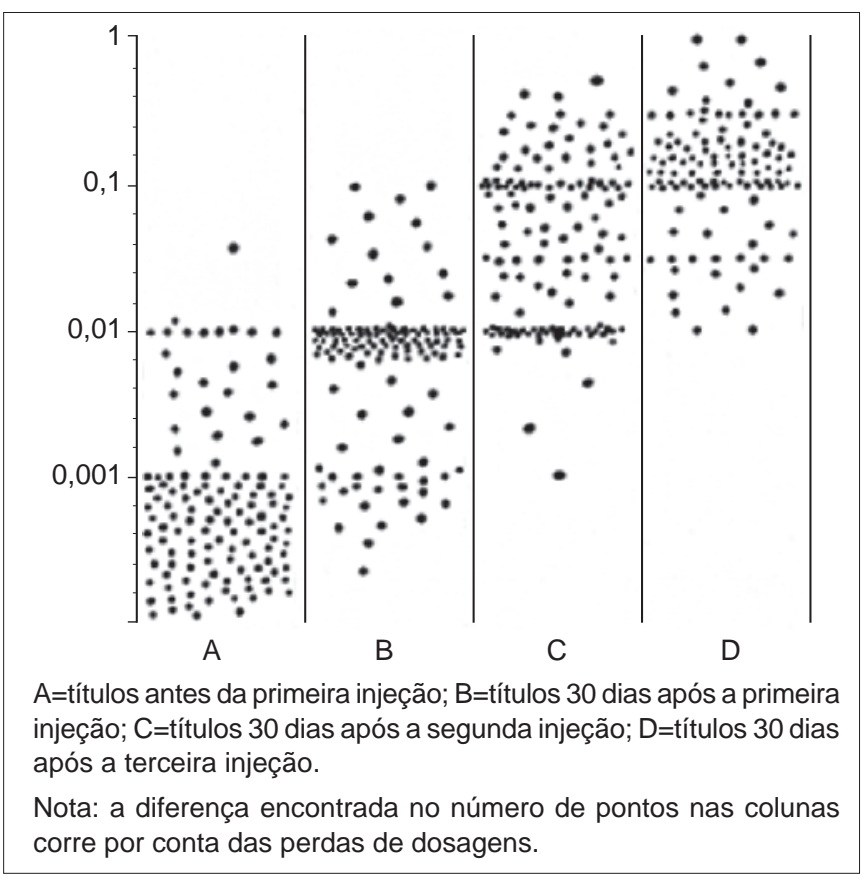

Figura 1 - Desenvolvimento do título de antitoxina tetânica em um grupo de 134 gestantes.

O controle da evolução da gravidez e das condições dos recém-nascidos foi obtido em 114 (76\%) gestantes vacinadas. Das 114 gestações estudadas, 112 (98\%) evoluíram sem intercorrências; em 96 delas (84\%) foi realizado parto normal, o que deu origem a $110(96,5 \%)$ nascidos vivos. Foi observado óbito em quatro fetos, sendo dois deles prematuros, um proveniente de mãe que apresentou pré-eclâmpsia e outro macerado. As anomalias congênitas ocorreram em dois recém-nascidos: dedo supra-numerário em um e pé torto em outro.

Em relação ao peso ao nascimento, $86(75 \%)$ apresentaram peso superior a $2.500 \mathrm{~g}$, sete $(6 \%)$ foram de baixo peso e 21 não tiveram o peso avaliado. A vacinação da gestante não parece ter exercido qualquer efeito nocivo sobre a gravidez e o feto. O percentual de prematuridade foi semelhante ao encontrado nos bairros operários da capital ( 8 a 10\%).

\section{Estudo nos recém-nascidos}

Foram colhidas 20 amostras de sangue do cordão umbilical de mães não-vacinadas com toxóide tetânico para titulação de antitoxina tetânica. Os dados obtidos mostraram, praticamente, ausência de antitoxina tetânica no sangue do cordão umbilical de seus recém-nascidos.

Em 42 casos foi possível obter o título de antitoxina nas gestantes e no sangue do cordão dos recém-nascidos. A transferência de anticorpos sofreu variações muito grandes,

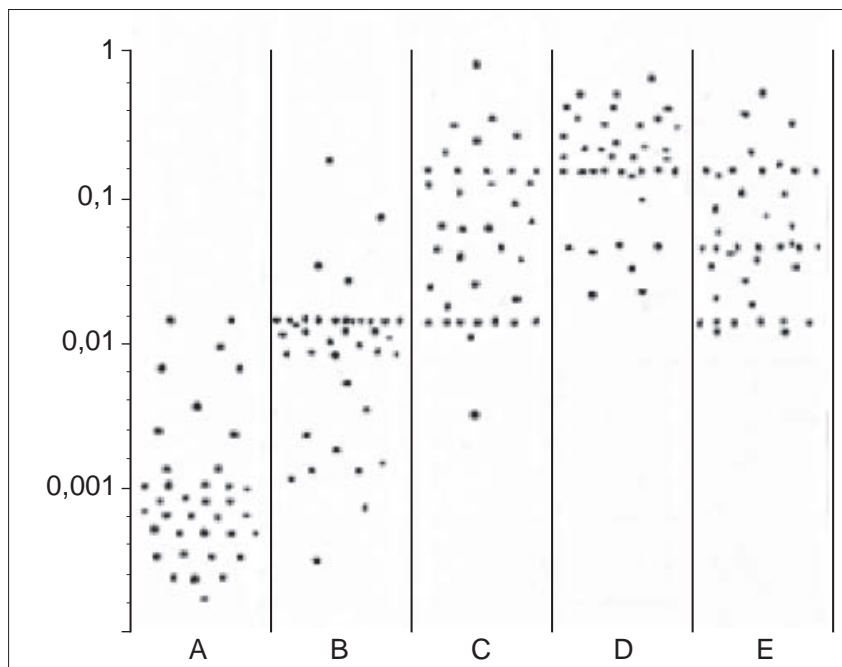

A=títulos antes da primeira injeção; $B=t$ títulos 30 dias após a primeira injeção; C=títulos 30 dias após a segunda injeção; $D=$ =títulos 30 dias após a terceira injeção; E=título obtido em sangues do cordão.

Nota: a diferença encontrada no número de pontos nas colunas corre por conta das perdas de dosagens.

Figura 2 - Desenvolvimento do título de antitoxina tetânica em um grupo de 42 gestantes e seus recém-nascidos.

mas, de um modo geral, observou-se que o título da mãe foi mais elevado que o do recém-nascido. Apenas duas crianças, dentre as 42 , não atingiram o nível de $0,01 \mathrm{U} / \mathrm{cm}^{3}$ de antitoxina. A Figura 2 registra estes dados, permitindo uma nítida avaliação do resultado da imunização.

\section{Estudo nas crianças}

Em cinco casos, foi possível titular a antitoxina tetânica na gestante, no sangue do cordão e, posteriormente, em amostras de sangue colhidas após o nascimento, encontrando-se níveis satisfatórios. Após o nascimento, verificou-se a queda do título em relação às amostras colhidas do sangue umbilical.

Em 32 crianças, com idades variáveis e cujas mães foram vacinadas, titulou-se a antitoxina tetânica a partir de coleta de sangue por punção venosa. Verificou-se que, mesmo após 15 dias de vida, ainda se demonstrava título satisfatório de antitoxina tetânica.

\section{Conclusões}

A vacinação da gestante com anatoxina tetânica promoveu nível de antitoxina para a proteção do tétano acidental e obstétrico. Obtida a imunidade básica, as doses de reforço praticadas de tempo em tempo promoveram a elevação do título e sua manutenção por período útil. A obtenção de títulos de antitoxina de $0,01 \mathrm{U} / \mathrm{cm}^{3}$ mostrou que a vacina- 
ção durante a gestação é capaz de conferir proteção contra a toxemia tetânica.

Os recém-nascidos de mães adequadamente vacinadas tiveram, em 95\% dos casos, nível de antitoxina tetânica no sangue do cordão, capaz de protegê-los contra o tétano umbilical. Os estudos realizados para verificar a duração do título de antitoxina no recém-nascido revelaram que ele é mantido em nível satisfatório até 15 dias depois, sendo esse nível diminuído com o passar do tempo.

A ausência de reações graves e de nocividade sugere que a vacinação com anatoxina tetânica seja um método de imunização muito bem aceito pelo público. A imunização da gestante com anatoxina tetânica deve ser o método indicado para combater a mortalidade neonatal por tétano umbilical, uma vez que os resultados são imediatos e a execução não depende de outros fatores, exceto a vontade do homem.

Com base nesses resultados, recomenda-se introduzir na rotina dos serviços pré-natais a vacinação com três doses de anatoxina tetânica, praticar a dose de reforço nas gestantes com imunidade básica já estabelecida e promover campanhas de vacinação das gestantes nas áreas onde a incidência do tétano umbilical mostrar-se particularmente elevada.

\section{Referências bibliográficas}

1. Bahia A. Tétano neonatal. Pediatr Puericult 1952;21:115.

2. Bergey $D \mathrm{H}$, Etris $\mathrm{S}$. Tetanus toxoid in prophylaxis against tetanus. J Infect Dis 1933;53:331

3. Bergev D H. Active immunization against tetanus infection with tetanus toxoid. J Infect Dis 1934;55:72.

4. Bergey $\mathrm{DH}$, Etris $\mathrm{S}$. Immunization of humans with alum precipitated tetanus toxoid. Am J Pub Health Nations Health 1934;24:582-6.

5. Bergey DH, Etris S. Tetanus toxoid. Clin Med Surg 1936;43:30-1.

6. Bergey $\mathrm{DH}$, Etris $\mathrm{S}$. Active immunization against tetanus infection with tetanus toxoid. J Immunol 1936;31:363-71.

7. Bigler JA. Tetanus immunization; 10 years study. AMA Am J Dis Child 1951;81:226-32.

8. Bradford WL, Day E, Martin F. Humoral antibody formation in infants aged 1 to 3 months injected with a triple (diphtheria-tetanus-pertussis) alum-precipitated antigen. Pediatrics 1949;4:711-8.

9. Carvalho AA, Braga NP, Atenhein D, Starusss A, Rocha HS. Tetano neonatorum. Pediat Prat 1950;21:57-66.

10. Chevalley M, Eliachar E. Tetanus in the newborn. Nourrisson 1951;39:56-78.

11. Cooke JV, Jones FG. The duration of passive tetanus immunity and effect on active immunization with tetanus toxoid. JAMA 1943;121:1201.

12. Cooke JV, Holowach J, Atkins JE Jr, Powers JR. Antibody formation in early infancy against diphtheria and tetanus toxoids. J Pediat 1948;33:141-6.

13. Cowles PB. Tetanus immunization. Yale J Biol Med 1937;9:409-16.

14. Cunha R. Progressos da vacinação contra o tétano na dependência do controle biológico do toxóide. O Hospital 1950;38:753.

15. D`Antona D, Valensin M. Superiorité de l'immunité antitétanique active sur I'immunité passive. Rev Immunol 1937;3:29.

16. D`Antona D. La vaccination contre lê tétanos. Rev Immunol 1952;16:1.

\section{Agradecimentos}

Estes estudos foram realizados por inspiração da OMS. Para a sua realização houve cooperação de uma Clínica Prénatal, uma Maternidade e um Instituto Científico. Os participantes da pesquisa dedicam os resultados à Organização das Nações Unidas (ONU) como uma modesta contribuição brasileira aos esforços empregados na melhoria da saúde dos povos.

Observação: este artigo é original. Em outra versão, ele teve uma distribuição limitada, mas nunca foi publicado em revista médica. Todos os autores participaram da concepção do projeto (AGM), execução clínica (AGM e MASZ) ou laboratorial (CSL), análise dos resultados (AGM e MASZ) e/ou redação (AGM e MASZ). A pesquisa foi previamente aprovada por comitê de ética $a d-h o c$ da Clínica Infantil do Ipiranga, conforme o uso na época, nessa instituição.

Nota do editor: o material aqui publicado foi compactado pelo Professor Jayme Murahovschi a partir do original datado de 1953. As referências são as originais e, por isso, nem todos os dados puderam ser recuperados, assim como a sua inserção no texto. Por isso sua disposição foi feita em ordem alfabética.

17. Debré R. Le colostrum des femmes vaccinées contre le tétanos ne contient pas d`antitoxine tétanique. Compt Rend Soc Biol 1930;103:383.

18. Descombey P. L`anatoxine tétanique. Compt Rend Soc Biol 1924;91:239.

19. Imunização ativa pelo toxóide tetânico. O Hospital 1943;24:995.

20. Evans DC. Active immunization against tetanus. Lancet 1941;1:628.

21. Falcão Neto JC. Determinação do grau de imunidade ativa contra o tétano pela prova de proteção em camundongos. Arq Inst Biol Exército 1947;8:107.

22. Falcão Neto JC. Novas observações sobre a formação de antitoxina tetânica em indivíduos vacinados. Arq Int Biol Exército 1948;9:76.

23. Figueira F. Elementos de patologia. Rio: Briguiet; 1929.

24. Finkelstein H. Trattato delle malattie del lattante. $3^{a}$ ed. Alemã. Milão: Soc Ed Lebraria, 1929.

25. Furtado RJ, Falcão Neto JC. Plano de imunização contra o tétano e as infecções tifóidicas no Exército Brasileiro. Arq Inst Biol Exército 1947;8:95.

26. Gold H. Studies on tetanus toxoid. I. Active immunization of allergic individuals with tetanus toxoid, alum precipitated refined. J Allergy 1937;8:230-45.

27. Gold H. Studies on tetanus toxoid. II. Active immunization of normal persons with tetanus toxoid, alum precipitated, refined. JAMA 1937;109:481-4.

28. Gold $\mathrm{H}$. On the value of a injection of tetanus toxoid (secondary stimulus) in active immunization against tetanus. J Lab Clin Med 1940;25:506.

29. Gold H. Active immunization against tetanus by means of tetanus toxoid alumprecipitated refined. J Lab Clin Med 1938;23:903-13.

30. Gomes de Mattos A, Lacaz CS. Contribuição para o estudo etiológico do tétano umbilical. Ped Prat 1951;22:1-12.

31. Grancher J, Comby J. Traité des meladies de l`enfance. $2^{\mathrm{a}}$ ed. Paris: Masson; 1904.

32. Hall WW. Active immunization against tetanus with tetanus toxoid. Mil Surgeon 1937;80:104 
33. Harvin JR. Tetanus neonatorum. J Pediat 1948;32:561.

34. Jones FG, Jamieson WA. Studies on tetanus toxoid. III - Antitoxic response in guinea pigs immunized with tetanus alum-precipitated toxoid followed by tetanus by tetanus spores. J Bact 1936;32:33-40.

35. Jones FG, Moss JM. Studies on tetanus toxoid, antitoxic titre of human subjects following immunization with tetanus toxoid and alum-precipitated toxoid. J Immuno 1936;30:115.

36. Jones FG, Moss JM. The antitoxic titers of human subjects following immunization with combined diphtheria and tetanus toxoid, alum precipitated. J Immunol 1937;33:173-81.

37. Jones FG, Moss JM. Studies on tetanus toxoid. II. The response of human subjects to an injection of tetanus toxoid one year after immunization. J Immunol 1937;33:183-90.

38. Knerr RP, Hottle GA. Determination of minute amounts of tetanus antitoxin in serum. J Infect Dis 1934;55:360.

39. Leach CN Zia SH, Khati L. An attempt to immunize newborn infants to tetanus neonatorum through the administration of tetanus toxoid to pregnant mothers. Am J Hyg 1936;24:439-45.

40. Lemetayer $\mathrm{E}$. Teneur en antitoxine spécifique du colostrums chez les femmes vaccines par le vaccine mixte antidiphthérique-antitétanique. Bull Acad Nat Med 1950;134:22.

41. Long PH. Medical progress and medical education during the war. JAMA 1946;130:983.

42. Louzada A. A profilaxia do tétano do recém-nascido. O Hospital 1951;39:41.

43. Magara $M$, Adukata $K$. L`immunization antitétanique et antidiphthérique du nouveau-né et de l`enfant par la vaccination des femmes enceintes, au moyen de laanatoxine. Compt Rend Soc Biol 1937;125:782.

44. McBride A. Tetanus immunization with alum precipitated toxoid. South M J 1937;30:565.

45. Murray R. Simultaneous immunization against diphtheria, tetanus and pertussis; problems inherent in production of multiple antigen. Am J Pub Health Nations Health 1950;40:686-90.

46. Mitchell AG, Nelson WE. Textbook of pediatrics. $4^{\text {a }}$ ed. Philadelphia: Saunders; 1945.

47. Nattan-Larrier L, Grasset E. De l'immunité antitétanique chez le nouveau-né. Compt Rend Acad Sc 1926;183:485-60.

48. Nattan-Larrier L, Grasset E. L`anatoxine tétanique et l'immunité antitétanique chez la mere et le nouveau-né. Ann L`Inst Pasteur 1927;41:848-61.

49. Nattan-Larrier L, Grasset E. Contribution a l’etude du passage des antigens et des anticorps a travers de placenta. Ann L'Inst Pasteur 1927;41:862-67.
50. Nobécourt P, Babonneix L. Traité de Médicine des enfants. Paris, Masson; 1934.

51. Organization Mondiele de Santé. Série de Rapports Techniques 1950;6:16.

52. Pelloja M. Lê tétanos expérimental par la toxine tétanique. Paris: Masson; 1951.

53. Pernetta C, Leite Ribeiro VR, Martins H. Estudos sobre a etiologia do tetanus neonatorum. Resultado da pesquisa do Clostridium tetani em 15 casos. O Hospital 1946;30:775.

54. Pernetta C. Terapêutica infantil. Rio de Janeiro: Guanabara, 1951.

55. Pfaundler M, Schossmann A. Tratado de pediatria. Milão: Vallardi; 1913.

56. Ramon G, Descombey P. L`anatoxine et la prophylaxie du tétanos chez le cheval et les animaux domestiques. Ann L`Inst Pasteur 1927;41:834-47.

57. Ramon G, Zoeller $\mathrm{CH}$. L`anatoxine tétanique et l'immunization active de Ihome vis-àvis du tetanus. Ann L’Inst Pasteur 1927;41:803-33.

58. Ramon G. Le principe des anatoxines e ses applications. Paris: Masson; 1950.

59. Ramon G, Richou R. De laction simulante de diverses suspensions bactériennes formolées (anavaccins), sur l’immunité conférée par laanatoxine tétanique. Compt Rend Acad Sc 1950;231:563.

60. Rosenau M J, Anderson J F. The standardization of tetanus antitoxin. Bol. $\mathrm{n}^{\circ}$ 43. USA: United States Hygienic Laboratory; 1908.

61. Smith CA. Fisiologia del recien nacido. Buenos Aires: Vergara; 1953.

62. Sneath PA. Development of tetanus antitoxin following administration of tetanus toxoid. JAMA 1934;102:1288.

63. Sneath PA, Kerslake EJ. Persistence of tetanus antitoxin in man following active immunization. Brit M J 1935;2:290-1.

64. Sneath PA, Kerslake EJ, Scurby F. Tetanus immunity: The resistance of guinea pigs to lethal spore doses induced by active and passive immunization. Am J Hyg 1937;25:464-76.

65. Ten Broeck C, Bauer $\mathrm{JH}$. The transmission of tetanus antitoxin through the placenta. Proc Soc Hyg Biol Med 1923;20:399.

66. VanDer Reis V. Importância e necessidade das imunizações activa e passiva do tétano. Inst Pinheiros 1949;12:4.

67. Veronest R. Soroterapia antitetânica. Referência às doses profiláticas e curativas relacionadas aos títulos de antitoxina circulantes. Rev Med Cir São Paulo 1951;11.

68. Wishart FO, Jackson LK. Tetanus toxoid. Canad J Pub Health 1948;39:181.

69. Zia SH, Kha-Ti L, Leach N. La teneur en antitoxine du sang de la mère et du nouveau-né après injection d`antitoxine tétanique de Ramon aux mères enceintes. Rev Immunol 1936;2:260-2. 